\title{
Comparison of three methods for culture confirmation of Neisseria gonorrhoeae strains currently circulating in the UK
}

\author{
A Turner, K R Gough, A E Jephcott
}

\begin{abstract}
Aims-To establish the current sensitivity of two commercial kits for culture confirmation of Neisseria gonorrhoeae strains circulating in the UK.

Methods-A total of 544 strains were studied (199 gonococci from male patients attending hospitals in the county of Avon, 204 unselected $\boldsymbol{N}$ gonorrhoeae isolates from male patients in Leeds, 20 strains referred to the Gonococcus Reference Unit because of difficulties with the Syva fluorescent antibody test (FAT), and 121 strains collected over a four year period which had not reacted with serotyping antibodies). Strains were tested by sugar utilisation in cysteine trypticase base agar (CTA test), the Phadebact Monoclonal GC Test and Syva MicroTrak Neisseria gonorrhoeae Culture Confirmation Test. The auxotype and serovar of each strain were also determined.
\end{abstract}

Results-The sugar utilisation test confirmed the identity of $99 \%(197 / 199)$ of gonococci from Avon and 97\% (198/204) of those from Leeds. The Syva FAT confirmed $76 \%(151 / 199)$ of isolates from Avon and $84 \%(171 / 204)$ of those from Leeds. The Phadebact test confirmed all but one isolate from the $\mathbf{4 0 3}$ strains from both cities. Half of the 20 referred FAT negative isolates also give a negative result in the Syva FAT; however, only $10 \%$ of the remainder gave a strong reaction in our laboratory. All serotyping antibody negative strains were negative in the FAT, although all these and all of the 20 strains that give a negative result in the FAT gave positive reactions in the other culture confirmation tests. Typing tests revealed a greater diversity amongst the FAT negative strains from Leeds than those from Avon.

Conclusions - Considerable differences in the sensitivity of the MicroTrak but not with the Phadebact or CTA tests were found for the identification of isolates from two geographically distinct areas of the UK. Our results suggest that the Syva FAT would not be suitable, if used alone, for culture confirmation in Avon or Leeds.

(f Clin Pathol 1995;48:919-923)

Keywords: Neisseria gonorrhoeae, identification, monoclonal antibodies, fluorescence antibody test.
The rapid identification of Neisseria gonorrhoeae in the routine bacteriological laboratory has been facilitated in recent years by the introduction of monoclonal antibody based kits. In the UK these have principally been the Syva MicroTrak Neisseria gonorrhoeae Culture Confirmation Test, which is a fluorescent antibody test (FAT) and the Phadebact Monoclonal GC Test which uses co-agglutination. Studies conducted at the time of their introduction showed good results. The FAT was found to have a specificity of $100 \%$ and a sensitivity between 98 and $100 \% .^{1-3}$

Young and Moyes evaluated the Phadebact co-agglutination test using 1367 neisseria isolates including 1080 gonococci. ${ }^{4}$ Only three gonococci failed to react in the test (sensitivity $99 \cdot 7 \%$ ) and no false positive reactions were found (specificity $100 \%$ ).

The PHLS Gonococcus Reference Unit (GRU) receives many cultures each year for confirmation of identity of strains for which the sending laboratories have found conflicting results in their routine tests. As a result of this the GRU became aware that some strains of Neisseria sp. isolated from patients in the UK, identified as $N$ gonorrhoeae in routine tests performed at the GRU, were failing to give a positive result in the MicroTrak test. In addition, the GRU had been aware for some time that the monoclonal antibodies used for serotyping, which are produced by Genetic Systems for Syva, were failing to react with some strains including those isolated from patients from Avon.

As a result of this experience a study was initiated to compare the performance of the FAT with two other culture confirmation tests for the routine identification of $N$ gonorrhoeae isolated in two cities in the UK. Correlations between reactivity in the FAT and the serovar and auxotype of the strain were also examined.

\section{Methods}

SOURCE OF $N$ GONORRHOEAE strains

A total of 544 strains were included in the study. These comprised 199 consecutive oxidase positive, Gram negative diplococci isolated on New York City agar from male patients attending hospitals in the county of Avon during the first 11 months of 1992. They were isolated from urethral swabs $(n=180)$, rectal swabs $(n=12)$, throat swabs $(n=6)$, and one eye swab. To compare the effectiveness of the tests with a wide range of gonococcal strains, 
isolates from a second city in the UK were also tested. $N$ gonorrhoeae strains $(n=204)$ isolated from 195 urethral swabs, five rectal swabs and four throat swabs collected from male patients in Leeds undertaking a therapeutic trial were used.

Also included in the study were 20 strains referred to the GRU because of difficulties with the Syva FAT and, except for a single strain isolated in September 1990, these were received between January 1992 and October 1993. Between 1988 and 1991 the GRU serotyped 4213 gonococcal strains and from these found 121 strains which did not react with the serotyping antibodies; these were also included in the study.

\section{CULTURE CONFIRMATION}

The 199 isolates from Avon were identified using three methods; sugar utilisation in cysteine trypticase agar (CTA test) (Becton Dickinson, Cockeysville, USA), ${ }^{5}$ the Phadebact Monoclonal GC Test (Boule Diagnostics AB, Huddinge, Sweden) and the Syva MicroTrak Neisseria gonorrhoeae Culture Confirmation Test (Syva, Palo Alto, USA), the latter two methods performed according to the manufacturer's instructions. Results of the FAT were scored as negative,,+++ , or +++ . Strains giving a negative result in any test had the test repeated and only repeated negative results were scored as negative in the analysis. Reactive strains that had given an initial negative result were allocated a reactive result. When results from all three tests did not agree the identity of each strain was taken as the result obtained from the majority of the tests. The strains referred from Leeds and elsewhere were confirmed as $N$ gonorrhoeae using the same tests.

\section{AUXOTYPING}

All strains were auxotyped using the defined medium of Copley and Egglestone to test for nutritional requirement for proline, arginine, hypoxanthine, and uracil. ${ }^{6}$ In addition, the ability of ornithine to replace a requirement for arginine was tested.

SEROTYPING

Monoclonal antibodies, raised against the major outer membrane protein I of $N$ gonorrhoeae, produced by Genetic Systems and supplied by Syva, were used to serotype strains. Six monoclonal antibodies were specific for protein IA strains and six were specific for protein IB strains. The co-agglutination reaction pattern with each panel was used in the nomenclature scheme of Knapp et al to determine the serovar. ${ }^{7}$

\section{Results}

The relative performance of the culture confirmation tests is shown in table 1 . The sensitivity of the CTA test for unselected strains of $N$ gonorrhoeae varied between $97 \cdot 1 \%$ and $99 \%$ for isolates from Leeds and Avon, respectively. Eight isolates failed to produce acid from glucose, maltose and sucrose. All eight gave positive results in the co-agglutination test and the FAT. The single strain that the Phadebact test failed to identify (from Leeds) gave a positive result for $N$ gonorrhoeae in both the CTA test and in the FAT. Neither the CTA sugars nor the Phadebact test failed to identify any of the strains referred to the GRU because of suspected failure to react in the FAT or any of the referred strains found by us to be non-reactive with the serotyping antibodies.

The sensitivity of the FAT in confirming unselected strains of $N$ gonorrhoeae varied between $75.9 \%$ and $83.8 \%$ for isolates from Avon and Leeds, respectively. The 81 strains which failed to react in the FAT all gave positive results for $N$ gonorrhoeae with the other tests. The FAT gave a positive result with 10 of 20 of the strains reported to be FAT negative by the referring laboratory; however, eight of 10 of the reactive strains gave a weak positive $(+)$ result and none gave a strong positive $(+++)$ result. As might be expected, all strains which failed to react with the panel of monoclonal serotyping antibodies also failed to react with the FAT.

Table 2 shows the distribution of auxotype/ serovar types found among the 199 Avon isolates and the number of those that failed to react in the FAT. Only two auxotypes were found among the FAT negative strains. Most (47 of 48 ) of the non-reacting strains were of the non-requiring (NR) auxotype. Forty of these 47 FAT negative strains also did not react with the serotyping antibodies. The only other auxotype found to be FAT negative was a single AHU isolate, one of only 16 strains of this auxotype found in the isolates from Avon.

Table 1 Performance of $\mathrm{N}$ gonorrhoeae culture confirmation tests

\begin{tabular}{|c|c|c|c|c|c|}
\hline \multirow[b]{3}{*}{ Test } & \multirow[b]{3}{*}{$\begin{array}{l}\text { Confirmatory } \\
\text { test result }\end{array}$} & \multicolumn{4}{|l|}{ Origin of strains } \\
\hline & & \multirow[b]{2}{*}{$\begin{array}{l}\text { Avon }(n=199) \\
\text { (sensitivity, \%) }\end{array}$} & \multirow[b]{2}{*}{$\begin{array}{l}\text { Leeds }(n=204) \\
\text { (sensitivity,\%) }\end{array}$} & \multicolumn{2}{|l|}{ Others } \\
\hline & & & & $\begin{array}{l}\text { FAT negative* } \\
\text { (sensitivity, \%) }\end{array}$ & $\begin{array}{l}\text { SNR+ }(n=121) \\
\text { (sensitivity, \%) }\end{array}$ \\
\hline CTA test & Positive $\ddagger$ & $197(99 \cdot 0)$ & $198(97 \cdot 1)$ & $20(100)$ & $121(100)$ \\
\hline Phadebact test & $\begin{array}{l}\text { Positive } \\
\text { Negative }\end{array}$ & $199(100)$ & $203(99 \cdot 5)$ & $20(100)$ & $121(100)$ \\
\hline FAT & $\begin{array}{l}\text { Positive } \\
\text { Negative }\end{array}$ & $\begin{array}{r}151(75 \cdot 9) \\
48\end{array}$ & $171(83 \cdot 8)$ & $\begin{array}{l}10(50) \\
10\end{array}$ & 121 \\
\hline
\end{tabular}

* Twenty strains referred to the GRU because of difficulties with Syva MicroTrak FAT.

† Strains which did not react with the serotyping antibodies.

$\neq$ Positive reaction for $N$ gonorrhoeae (acid produced from glucose, not from maltrose or sucrose)

Negative reaction for $N$ gonorrhoeae (no acid produced from glucose, maltose or sucrose). 
Table 2 Auxotype/serovar types found in $\mathrm{N}$ gonorrhoeae strains isolated in Avon, and the number giving negative results in the MicroTrak Neisseria gonorrhoeae Culture Confirmation Test (FAT)

\begin{tabular}{|c|c|c|c|c|c|c|c|c|c|c|}
\hline \multirow[b]{2}{*}{ Serovar } & \multicolumn{10}{|c|}{ Number of isolates (number FAT negative) } \\
\hline & $\mathrm{Arg}^{-}$ & $\begin{array}{l}\text { Arg- } \\
\text { Hyp- }\end{array}$ & $\underset{\text { Ura }^{-}}{A r g^{-} H_{y p^{-}}}$ & Hyp $^{-}$ & Non-requiring & $P_{r o}^{-}$ & $\begin{array}{l}\mathrm{Pro}^{-} \\
\mathrm{Arg}^{-}\end{array}$ & $\begin{array}{l}P r o^{-} \mathrm{Arg}^{-} \\
\left(\mathrm{orn}^{-}\right) \mathrm{Ura}\end{array}$ & $\begin{array}{l}\text { Not } \\
\text { tested }\end{array}$ & Total \\
\hline $\begin{array}{l}\text { IA1 } \\
\text { IA16 }\end{array}$ & & 1 & $\begin{array}{l}2 \\
3(1)\end{array}$ & & & & & & 1 & $\begin{array}{l}4 \\
3(1)\end{array}$ \\
\hline IA18 & & & 1 & & & & & & & 1 \\
\hline IA2 & & 3 & 10 & & & & & & & 13 \\
\hline IA4 & & & & & 1 & & & & & 1 \\
\hline IA5 & & & & & 1 & & & & & 1 \\
\hline IA8 & & & & & & & 1 & & & 1 \\
\hline IB1 & & & & 7 & 4 & 3 & & & & 14 \\
\hline IB14 & & & & 1 & & & & & & 1 \\
\hline IB16 & 1 & & & & 1 & & & & & 2 \\
\hline IB2 & 14 & & & 2 & $4(1)$ & 2 & & 2 & & $24(1)$ \\
\hline IB20 & & & & & $6(6)$ & & & 1 & & $7(6)$ \\
\hline IB3 & 1 & & & 38 & 26 & 2 & & & & 67 \\
\hline IB4 & & & & & 2 & & & & & 2 \\
\hline IB5 & & & & & 1 & & & & & 1 \\
\hline IB6 & & & & & 5 & & & & & 5 \\
\hline IB7 & & & & & 1 & 6 & & & & 7 \\
\hline Total & 16 & 4 & $16(1)$ & 48 & 93(47) & 14 & 1 & 3 & 1 & $199(48)$ \\
\hline
\end{tabular}

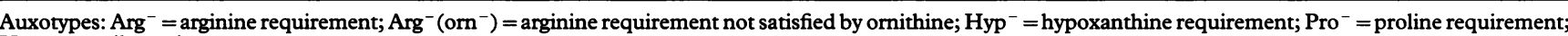
$\mathrm{Ura}^{-}=$uracil requirement.

Table 3 Auxotype/serovar types found in $\mathrm{N}$ gonorrhoeae strains isolated in Leeds, and the number giving negative results in the MicroTrak Neisseria gonorrhoeae Culture Confirmation Test (FAT)

\begin{tabular}{|c|c|c|c|c|c|c|c|c|c|c|c|}
\hline \multirow[b]{2}{*}{ Serovar } & \multicolumn{11}{|c|}{ Number of isolates (number FAT negative) } \\
\hline & $\mathrm{Arg}^{-}$ & $\begin{array}{l}A r g^{-}\left(\mathrm{orn}^{-}\right) \\
\text {Hyp }^{-}\left(U r a^{-}\right.\end{array}$ & $A r g^{-} H y p^{-}$ & $\begin{array}{l}\text { Arg }^{-} \\
\text {Hyp }^{-} \text {Ura }^{-}\end{array}$ & $H_{y p^{-}}$ & Non-requiring & $P_{r o}^{-}$ & $\begin{array}{l}\mathrm{Pro}^{-} \\
\mathrm{Arg}^{-}\end{array}$ & $\begin{array}{l}\mathrm{Pro}^{-} \mathrm{Arg}^{-} \\
\left(\mathrm{orn} \mathbf{H}^{-}\right) \mathrm{Ura}^{-}\end{array}$ & $\begin{array}{l}\mathrm{Pro}^{-} \mathrm{Arg}^{-} \\
\mathrm{Hyp}\end{array}$ & Total \\
\hline IA2 & 1 & 2 & 2 & $26(2)$ & & 4 & & & & 1 & $36(2)$ \\
\hline IA21 & & & 1 & & & & 1 & & & & 2 \\
\hline IA3 & 1 & & & 1 & & 1 & & & & & 2 \\
\hline IA6 6 & & & & & & $4(1)$ & $4(2)$ & 1 & & & $9(3)$ \\
\hline IB16 & & & & & & 1 & & & 1 & & 2 \\
\hline IB2 & $13(1)$ & & & & & 32 & 3 & & 17 & & $65(1)$ \\
\hline IB20 & & & & & 1 & & & & & & 1 \\
\hline IB3 & $16(1)$ & & 2 & & 2 & 1 & 2 & & & & $22(1)$ \\
\hline IB4 & & & & & & & & 1 & & & 1 \\
\hline IB6 & 2 & & 1 & & & 10 & 1 & & & & 14 \\
\hline IB7 & & & & & & & 4 & & & & 4 \\
\hline 6D9 & & & 1 & 2 & & & & & & & 3 \\
\hline IB20/6D9 & & & & & & 1 & & & & & 1 \\
\hline Non-reactive & & & & & $1(1)$ & $24(24)$ & & & & & $25(25)$ \\
\hline Total & $42(3)$ & 2 & 7 & $31(2)$ & $3(1)$ & $83(25)$ & $15(2)$ & 2 & 18 & 1 & 204(33) \\
\hline
\end{tabular}

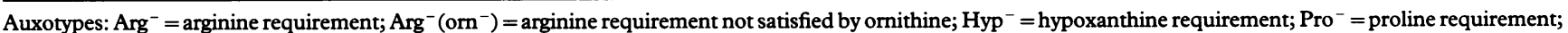
$\mathrm{Ura}^{-}=$uracil requirement.

The overall range of serovars and auxotypes found in the 204 isolates from Leeds (table 3) was similar to that found in Avon, although the predominant auxotype/serovar types differed. The differences in the strains circulating in the two cities were also reflected in the differences found in the FAT negative strains. In Leeds the FAT negative serovars and auxotypes were more varied, although the predominant strain (NR/non-reactive) was the same in both cities. In Avon six isolates of auxotype/serovar class NR/IB20 were identified and all six failed to react with the FAT. However, no NR/IB20 strains were isolated in Leeds. The single IB20 strain isolated in Leeds required hypoxanthine for growth and had a moderately positive reaction in the FAT.

Strains giving weak positive $(+)$ reactions were not evenly distributed among the serogroups found in isolates from Avon or Leeds. Twenty five FAT reactive IA strains were isolated in Avon during the study, 11 of which gave a weak positive reaction. Ten of the 25 FAT reactive IA strains belonged to auxotype/ serovar class AHU/IA2 and six of these gave a weak reaction in the FAT. Similarly, 23 of 47 FAT reactive IA strains isolated in Leeds gave a weak reaction in the FAT. Twenty four of the reactive IA strains were AHU/IA2 and 13 of these gave weak positive reactions. These results contrast with the FAT results obtained from protein IB strains where only 25 of 126 and nine of 124 reactive strains from Avon and Leeds, respectively, gave weak positive results.

The strains referred to the GRU because of suspected non-reactivity in the FAT (table 4) showed almost as much variation in auxotype/ serovar types in the strains confirmed to be FAT negative as the isolates from Avon or Leeds. Four different auxotype/serovar types were found but only $30 \%$ of strains belonged to the $\mathrm{NR} /$ non-reactive type compared with $83 \%$ of isolates from Avon and $73 \%$ from Leeds.

All 121 strains which failed to react with the panel of monoclonal serotyping antibodies belonged to serogroup WII/III (protein IB strains) as determined with the Phadebact test. 
Table 4 Auxotype/serovar types found in $\mathrm{N}$ gonorrhoeae strains referred to the GRU with reported negative results in the MicroTrak Neisseria gonorrhoeae Culture Confirmation Test (FAT), and the number confirmed to give negative results in the FAT at the GRU

\begin{tabular}{|c|c|c|c|c|c|c|}
\hline \multirow[b]{2}{*}{ Serovar } & \multicolumn{6}{|c|}{ Number of isolates (number FAT negative) } \\
\hline & $\mathrm{Arg}^{-}$ & Hyp & Non-requiring & $\begin{array}{l}\text { Pro }^{-} \mathrm{Arg}^{-} \\
\mathrm{Hyp^{- }}\end{array}$ & $\begin{array}{l}\mathrm{Pro}^{-} \mathrm{Arg}^{-} \\
\left(\mathrm{orn}^{-}\right) \mathrm{Ura}^{-}\end{array}$ & Total \\
\hline IB1 & & & $1(1)$ & & & 1 \\
\hline IB2 & 2 & & 1 & & $2(2)$ & $5(3)$ \\
\hline IB3 & $4(4)$ & 1 & & & & $5(4)$ \\
\hline & & & 5 & & & \\
\hline Non-reactive & & & $3(3)$ & & & $3(3)$ \\
\hline Not tested & & & & 1 & & 1 \\
\hline Total & $6(4)$ & 1 & $10(4)$ & 1 & $2(2)$ & $20(10)$ \\
\hline
\end{tabular}

Auxotypes: $\mathrm{Arg}^{-}=$arginine requirement; $\mathrm{Arg}^{-}\left(\mathrm{orn}^{-}\right)=$arginine requirement not satisfied by ornithine; $\mathrm{Hyp}^{-}=$hypoxanthine requirement; $\mathrm{Pro}^{-}=$proline requirement; Ura ${ }^{-}=$uracil re- $^{-}$ quirement. eight were not FAT negative but gave a weak reaction. This suggests that the referring laboratories had some difficulty in determining the point at which significant fluorescence begins and this may result in an even higher incidence of negative results in general laboratories than we have detected in the current study. Our results suggest that a further 26 isolates from Avon and 32 from Leeds could have been misidentified by inexperienced laboratory staff in this way.

The first survey to report the incidence of FAT negative strains was performed in Denver, USA, by Beebe et al. ${ }^{11}$ This group reported that $18(4.6 \%)$ of 395 of isolates did not react with the FAT. This represents a lower incidence than in the current study where $24.1 \%$ of isolates from Avon and $16 \cdot 2 \%$ from Leeds did not give positive results in the FAT. It is interesting that in both countries the predominant auxotype/serovar type of the FAT negative strains was NR/non-typable. This auxotype/serovar type accounted for $67 \%$ of FAT negative strains in the USA, $83 \%$ from Avon and $73 \%$ from Leeds. Overall, the range of auxotypes and serovars found in Avon and Leeds was similar. The predominant auxotype/ serovar type did vary; in Avon strains belonging to the NR/non-typable class (all FAT negative) accounted for $20 \%$ of all isolates, whereas in Leeds these accounted for $12 \%$, with NR/IB2 strains (all FAT positive) being the most common, comprising $16 \%$ of all isolates.

Among Avon and Leeds isolates, weak positive reactions in the FAT were more common among IA serogroup strains than among IB strains. In both centres about half of IA strains gave a weak result compared with $19 \%$ of FAT reactive IB strains from Avon and $7 \%$ from Leeds. By contrast, only one of the strains referred to the GRU because of negative FAT results belonged to serogroup IA, and this strain gave a weak reaction in the FAT.

An additional similarity found between isolates from Avon and those reported in the USA $^{11}$ was that many isolates with the IB20 serovar were FAT negative. Six of seven IB20 strains from Avon were negative, while in the study from the USA five such negative strains were found although the denominator is not given. Strains classified as serovar IB20 in the serotyping scheme ${ }^{7}$ used in the current study show reactivity with only a single monoclonal antibody (3C8).

The general reference work of the GRU revealed a further 121 FAT negative strains among those isolates sent for confirmation of their increased resistance to antibiotics. These were tested in the FAT because of their lack of reactivity with the serotyping antibodies and suggests that a further population of antibiotic resistant FAT negative strains exists apart from those commonly encountered in Bristol and Leeds.

The results obtained in this study suggest that the Syva FAT would be unsuitable, if used alone, for culture confirmation in Avon or Leeds. Laboratories considering the use of monoclonal antibody based kits for culture confirmation should perform their own survey limited number of epitopes false negative rests can be predicted. ${ }^{10}$

Twenty strains were referred to the GRU as non-reactive in the FAT and although $50 \%$ of these were confirmed as negative, a further 
to determine the local incidence of non-reacting strains.

We thank Dr C A Ison for supplying the monoclonal serotyping antibodies, and Mary Hemming and Pippa Davis for their excellent technical assistance.

1 Laughon BA, Ehret JM, Tanino TT, Van der Pol B, Handsfield $\mathrm{HH}$, Jones RB, et al. Fluorescent monoclonal antibody for confirmation of Neisseria gonorrhoeae cultures. 千 Clin Microbiol 1987;25:2388-90.

2 Welch WD, Cartwright G. Fluorescent monoclonal antibody compared with carbohydrate utilization for rapid idencompared with carbohydrate utilzation for rapid iden-
tification of Neisseria gonorrhoeae. 7 Clin Microbiol 1988; tification

3 Moyes A, Young H. Fluorescent monoclonal antibody for the confirmation of Neisseria gonorrhoeae. Med Lab Sci 1989;46:6-10.

4 Young $\mathrm{H}$, Moyes A. Utility of monoclonal antibody coagglutination to identify Neisseria gonorrhoeae. Genitourin Med 1989;65:8-13.

5 Morello JA, Janda WM, Bonhoff $M$ Neisseria and Branhamella. In: Lennette EH, Balows A, Hausler WJ Jr,
Shadomy HJ, eds. Manual of clinical microbiology. 4th edn. Washington DC: American Society for Microbiology, 1985:176-92.

6 Copley CG, Egglestone SI. Auxotyping of Neisseria gonorrhoeae isolated in the United Kingdom. If Med Micnobiol 1983;16:295-302.

7 Knapp JS, Tam MR, Nowinski RC, Holmes KK, Sandstrom EG. Serological classification of Neisseria gonorthoeae with use of monoclonal antibodies to gonococcal outer membrane protein I. $f$ Infect Dis 1984;150:44-8.

8 Walton DT. Fluorescent-antibody-negative penicillinaseproducing Neisseria gonorrhoeae. $\mathcal{F}$ Clin Microbiol 1989; producing

9 Boehm DA. Bemhardt $M$, Kuranski TA, Pennell DR Schell RF. Evaluation of two commercial procedures for rapid identification of Neisseria gonorrhoea using a refrapid identification of Neisseria gonorrhoea using a refMicrobiol 1990;28:2099-2100.

10 Ison CA. Methods of diagnosing gonorrhoea. Genitourin Med 1990;66:453-9.

11 Beebe JL, Rau MP, Flageolle S, Calhoon B, Knapp JS Incidence of Neisseria gonorrhoeae isolates negative by Syva direct fluorescent-antibody test but positive by Genprobe Accuprobe Test in a sexuslly transmitted disease clinic population. f Clin Microbial 1993;31:2535-7. 